\title{
Application of a Dynamic Collaborative Learning Oriented Knowledge Model
}

\author{
Jianhui Shi \\ Department of Humanistic and Social Science \\ Institute of Disaster Prevention \\ Sanhe, Hebei, China \\ e-mail: stone@fzxy.edu.cn
}

\author{
Lihua Liu \\ Department of Physical Education \\ Institute of Disaster Prevention \\ Sanhe, Hebei, China \\ e-mail: liulihua@fzxy.edu.cn
}

\begin{abstract}
Collaborative learning is becoming a very important teaching mode in course teaching. This paper puts forward a dynamic collaborative learning oriented knowledge model and course teaching mode, and then designs the process of course teaching. Different leaning modes are used for different kind of course knowledge to fulfill the collaborative leaning and personalized individual leaning.
\end{abstract}

Keywords-Dynamic collaborative learning;Knowledge model;personalized individual leaning

\section{INTRODUCTION}

In recent years, the collaborative learning in class environment and network environment has been studied deeply.Now some achievement is obtained in teaching practice based on class environment collaborative leaning. Whether collaborative learning in class environment or in network environment, they all are the process of learning of individual students by grouping. During the process of learning, students communicate, negotiate and talk each other to share their achievements.Learning group reflects the relationship network between different individuals, the premise of the achievement is effective collaboration between the individuals. ${ }^{[1]}$ The collaborative mode could be divided into formal collaborative mode and free collaborative mode. ${ }^{[2]}$ During the process of collaborative learning, the collaborative group researches the problem amply used all kinds of method such as share learning resources, negotiation, discussion and collaboration etc, and in order to obtain the best approach to achievement.

In the whole process of course teaching, each subject in teaching design is relatively independent.No matter what method is used to construct the collaborative group, the members of the group are fixed.The task is equal to all the students.So,the task of collaborative learning is synthetically design the knowledge in the whole field, it cannot design individually.This paper puts forward a dynamic collaborative learning oriented knowledge model and course teaching mode,and then designs the process of course teaching.Different leaning modes are used for different kind of course knowledge to fulfill the collaborative leaning and personalized individual leaning.

\section{DESIGN OF THE KNOWLEDGE MODEL}

This paper constructs a relation model for multiple kind courses based on the viewpoint of constructivism, which could be divided into three levels, that is knowledge point level, application of knowledge point level and synthetic application of knowledge point level. In the mean time, the teaching process is divided into three steps dynamically according to the teaching aim and student's model, which are autonomous learning, horizontal collaboration and vertical collaboration.

The design idea of the relation model are: (1) The process of autonomous learning: setting up the learning target according to the learner's own characteristics, learners learning autonomously; (2) The process of horizontal collaboration: grouping the learners according to the learning progress and the synthetic information, and accomplish it through the collaboration of the group; (3) The process of vertical collaboration: grouping the learners according to the learning status of the former two phases and the other aspect of synthetic information, and accomplish it through the collaboration of the group.

The relation of all the modules is collaboration. Figure 1 is the structural diagram of the dynamic collaborative learning knowledge model. The personality analysis module analyzes the different learning styles, learning habits, degree of knowledge mastery, cognitive level and collaborative ability of different learners; in order to accomplish personally autonomous learning for autonomous learning module through resource dispatch module and provide scientific reason for reasonable grouping the grouping module. Status tracing module records the status information in all the phases of the learning for learners, in order to group reasonably and make the information library of the learners more abundance.

\section{PARTITION OF THE KNOWLEDGE IN TEACHING FIELD}

According to the teaching theorem of the learning theory of constructivism, the foundation of knowledge model must consider the factor of cognitive structure and its constructive strategy and idea, only consider the basic knowledge and its semantic relation is not acceptable. In other words, knowledge model must integrate knowledge application model and its contractual relation and basic knowledge and its semantic relation. So, knowledge in the teaching field could be divided into knowledge point level, application of knowledge point level and application of multiple knowledge point level, they are managed by knowledge point module, application of knowledge point module and application of multiple knowledge point module respectively. 
Knowledge point is divided systematically and scientifically by teaching masters according to the characteristics of the subject and actual teaching process. The basic rule of the partition is to ensure the partial integrity and overall unity. In order to accomplish the individualized instruction, every knowledge points should be given a relevant attribute; the control strategy is established based on it. The knowledge point module manages the corresponding teaching courseware and material library. Except this, modules also can measure the knowledge structure.

The application of knowledge point is the description and application of the learning unit; it is also the description of the application rule and experience of the learning knowledge unit. It can also be used in understand, learning and disposal of similar questions. The question design on the one hand considering the relation with knowledge point, on the other hand considering whether it is suitable for collaborative learning. If it is fit for the collaborative learning, the number of the learner group, and their responsibility and demand need be designed too. The application of knowledge point module also has the function to evaluate the knowledge structure, measurement and the achievement of the collaborative learning.

The synthetic application of multiple knowledge point is the knowledge application in bigger granularity. The design of question is collaborative learning oriented, the number of the member and their responsibility and demand should be defined. The synthetic application of multiple knowledge point is also has the function to evaluate the knowledge structure and the achievement of the collaborative learning.

\section{APPLiCATION TO COURSE TEACHING}

Collaborative learning has several modes.

1. Task driving teaching mode

In this mode, a questionnaire should be made before course learning, and students will be grouped rationally after the questionnaire. ${ }^{[3]}$

2. Collaborative independent learning mode

In this mode, students will be mixed grouped considering their achievement, ability, sex and family background etc. ${ }^{[4]}$

3. Network environment learning

This mode breaks through the time and spatial barrage in traditional education, collaborative learning under the help of network. [5] Students are grouped based on learning task, transmission mode, individual characteristics and the total number etc. ${ }^{[6]}$

The design of the process of course teaching can be divided into four steps.

1. The classification of the collaborative learning.

1) Static collaborative learning.

According to the properties of the problem and total aims, several different study groups are organized. If the teacher thinks the instruction and help should be useful during the process of group learning, he should join the group. ${ }^{[1]}$ Figure 2 is the schematic map of static collaborative learning.

2) Dynamic collaborative learning.

The mode of collaborative learning is flexible; the collaborative groups can be allocated flexibly according to recent learning circumstances and characteristics of the learners. The members in the collaborative group can join in other groups. Figure 3 is the schematic map of dynamic collaborative learning.

2. The process of course teaching

The process of course teaching (Figure 4) includes following steps:

1) Make the learning task

2) Design the learning contents

3) Personalized individual learning

4) Collaboration between groups

5) Collaboration within groups

3. Evaluation of the learning effect

Three phase to evaluate the learning effect: the first phase is test score; the second phase is self-evaluation and teacher evaluation; the third phase is group evaluation, inter-group evaluation and teacher evaluation.

4. The roles of teacher

The roles of teacher are as follows:

1) Design the teaching task and learning contents; 2) distinguish, development, aggregation and use the course resources; 3) solving common problem and individual guidance; 4) strengthen the collaboration within the group members and the collaboration and contest between groups; 5) evaluate individual and collaborative learning objectively.

\section{EXPERIMENT AND ANALYSIS}

The experimental course is "computer graph and image". The teaching environments are class teaching and network teaching. The students are from three grades and different classes. Through the comparative analysis, the dynamic collaborative learning oriented knowledge model has several advantages in class teaching as follows:

\section{A. Reflect the personalized individual learning.}

B. Teaching different students according to their own characteristics.

C. The course teaching mode has wide scope of application.

The course teaching based on the dynamic collaborative learning is always students centered whether during the process of teaching contents design, or during the process of individual and collaborative learning. This paper is a new try of collaborative learning and hope to find new research thoughts in new view angle.

\section{ACKNOWLEDGEMENT}

This work was supported by Institute of Disaster Prevention teaching construction and teaching research project under Grant 2012A10.

\section{REFERENCES}

[1] Sleeman D, Brown J S. Intelligent tutoring systems [M]. NewYork: Academic Press, 1982.

[2] Zhao Jian Learning community-a sociocultural analysis to learning [M]. East China normal university press, 2006. 
[3] Slavin, R. E. Research on cooperative learning and achievement:What we know, what we need to know [J]. Contemporary Educational Psychology, 1996, (21): 43-69.

[4] Webb, N. M. Peer interaction and learning in small groups.[J].International Journal of Educational Research, 1989, (13):21-40.
[5] Chen li. The Quality of Social Interactionamong Students in an Asynchronous Interactive Environment:A Case Study of Online Discussion in Distance Educator Training. [J] China distance education, 2004, (4): 19-22.

[6] Knowledge Building and Collective Wisdom Advancement in Virtual Learning Communities. [M]. Educational science publishing house, 2005.

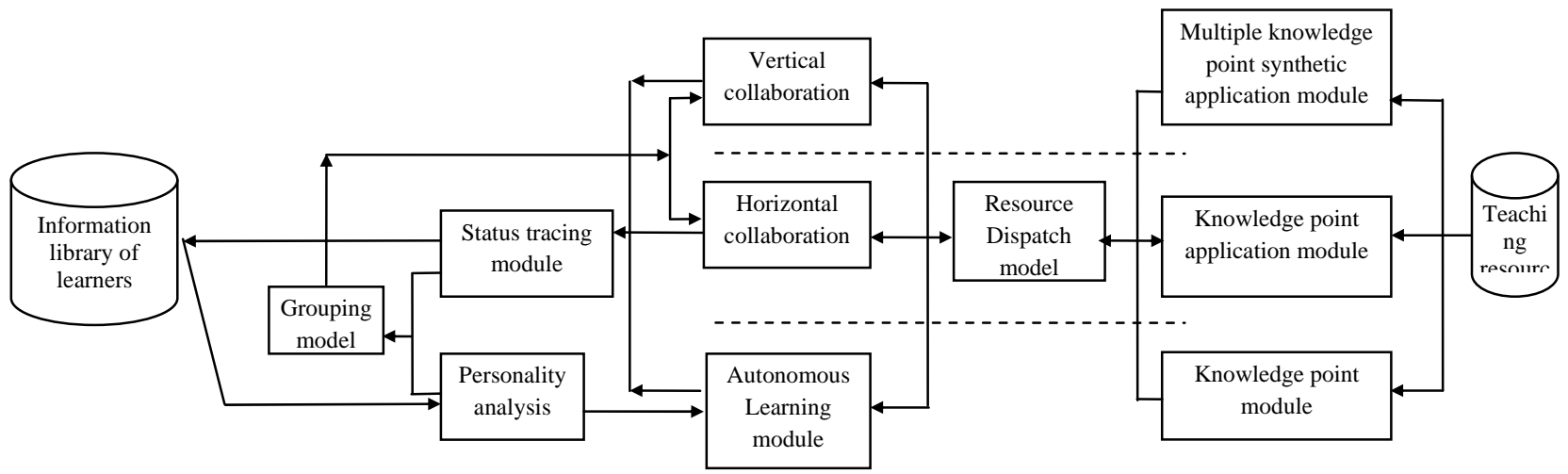

Figure 1 Structural diagram of the dynamically collaborative learning knowledge model

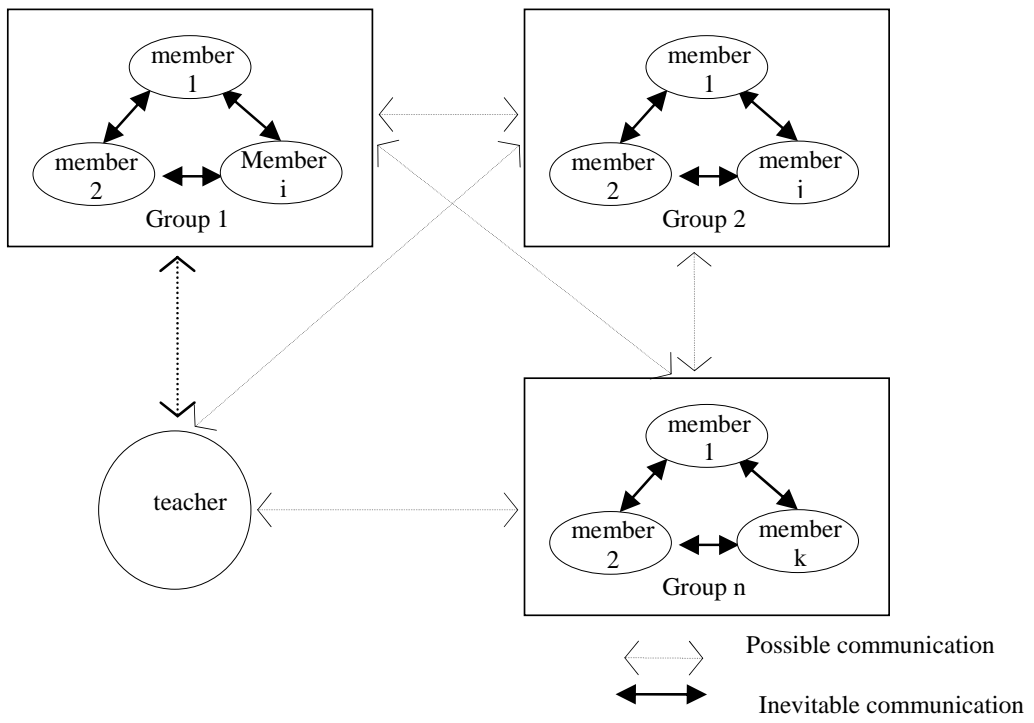

Figure 2 The schematic map of static collaborative learning 


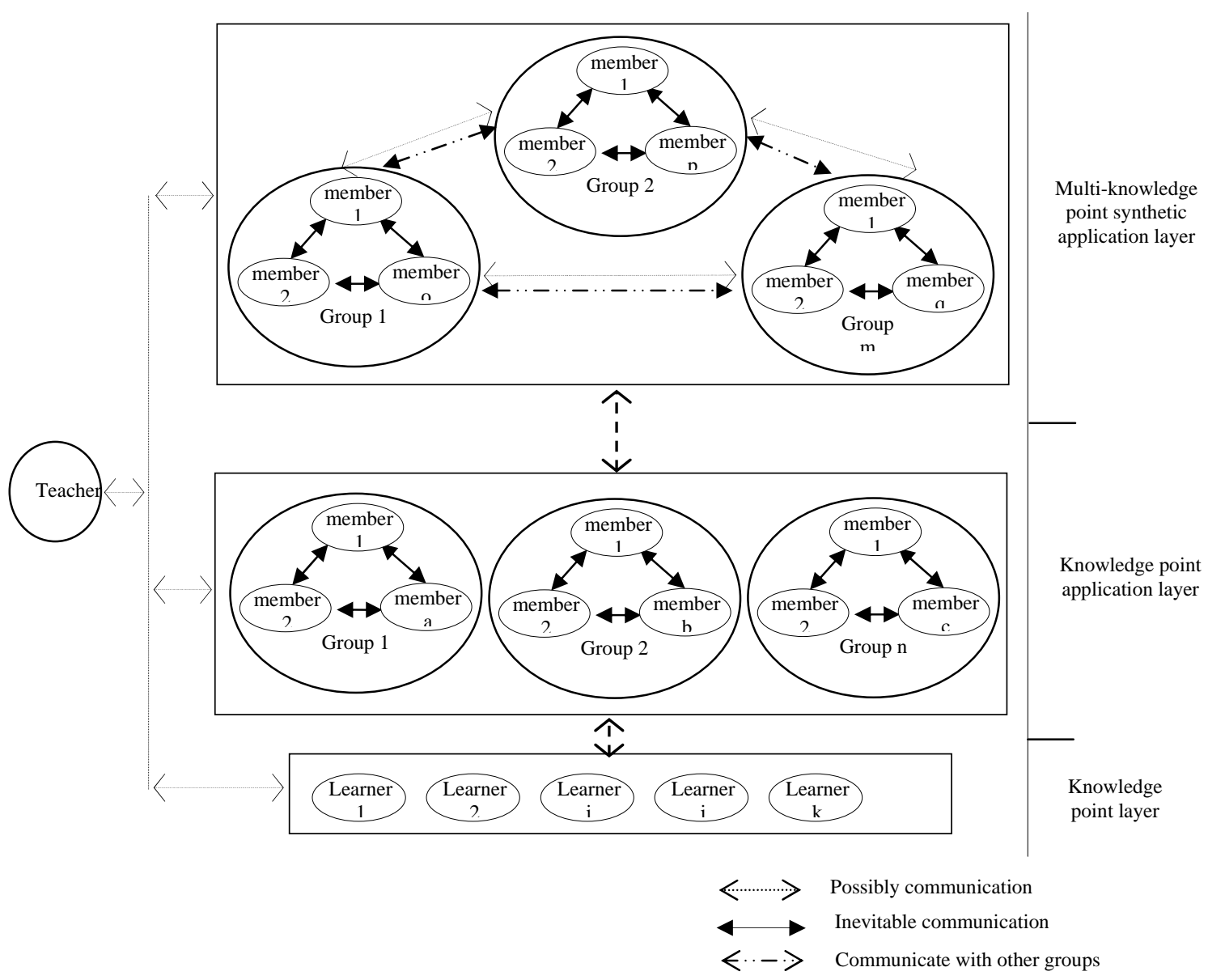

Figure 3 The schematic map of dynamic collaborative learning

The aim is attained, enter the next learning unit

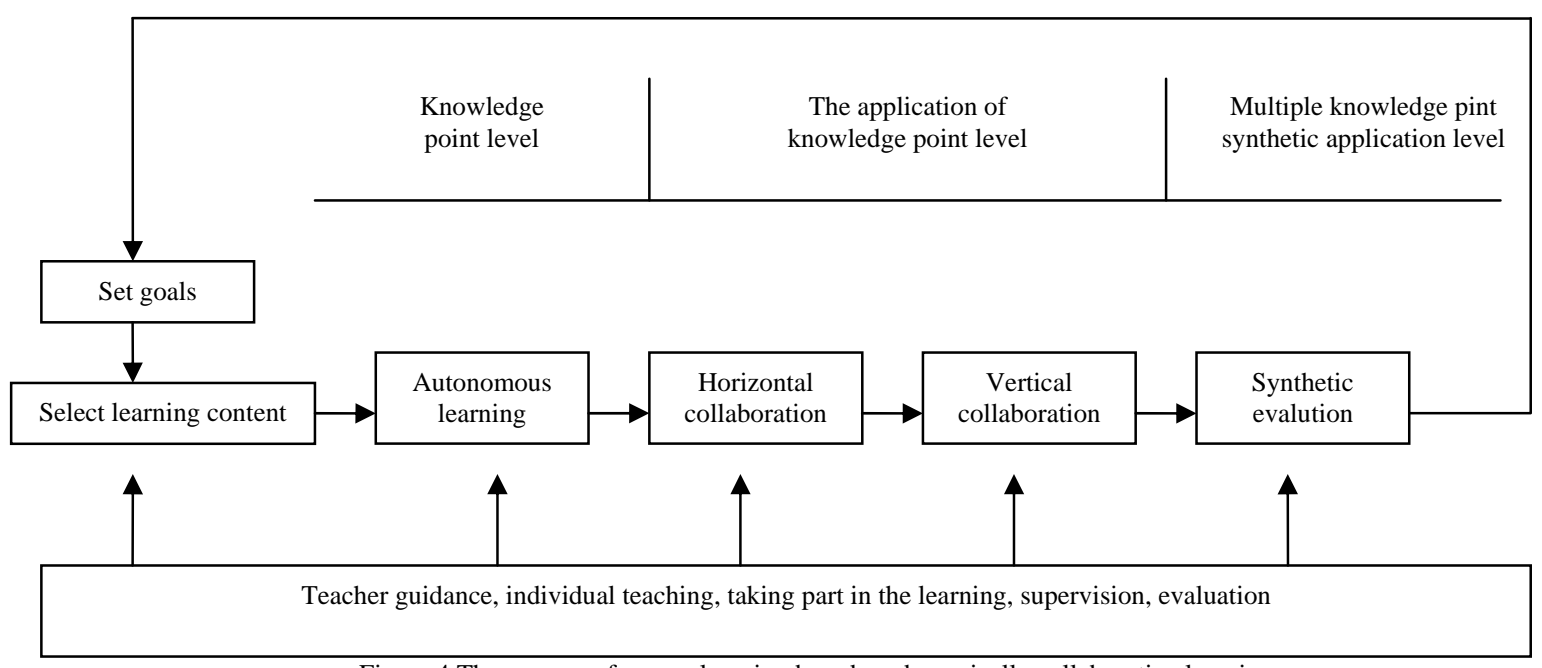

Figure 4 The process of course learning based on dynamically collaborative learning 